\title{
Tefsire Etki Eden Kırâat Farklılıkları Bakımından Yûsuf Sûresi
}

\section{Fatih CANKURT *}

\section{Özet}

Kur'ân-1 Kerîm, Hz. Peygamber'in sünneti ile beraber İslâm Dini'nin temelini oluşturan en önemli unsurdur. Bu unsurun her kesimden insanın anlayabilmesi, yaşayabilmesi için açılanmaya, tefsir edilmeye ihtiyacı vardır. Bunun için tefsir ilmi İslamî ilimler içerisinde önemli bir yer teşkil etmektedir. Kur'an tefsir edilirken onu en doğru biçimde anlayabilmek için indirilmiş olduğu toplumun sosyal ve coğrafi özelliklerinin dikkate alınma zorunluluğu olduğu muhakkaktır. Kur'an okuyuşundaki farklılıkları ele alan kırâat ilmi de Tefsir'den ayrı düşünülemeyecek bir kaynaktır ki kırâat ilminin konusunu oluşturan okuyuş farklılıkları da Kur'an'ın indirildiği toplumun dil özellikleri ve bu özelliklere göre okumaya müsaade edilmiş olması ile ortaya çıkmıştır. Bu çalışmada Kur'an'ın farklı okunuş biçimleri ve bu okuyuş biçimlerinin tefsire etkilerine örnek teşkil etmesi bakımından Yûsuf Sûresi ele alınmıştır.

Anahtar Kelimeler: Kur'an, Tefsir, Kırâat

\section{Reading Differences Affecting to Tafsir of Surah Yusuf}

\begin{abstract}
The Quran, the Sunnah of the Prophet of Islam, Hazrat, together with them important element. This feature will be explained to people from all walks of life to understand, needs to be the paraphrase. To Paraphrase the science of Islamic sciences constitute an important place within it. Quran Tafsir, while it is them ostaccurate way to take into account the social and geographical characteristics of the reduced, no offense, is the obligation of the community. Quran Recitation and Tafsir separated from the science of differences cannot be regarded as constituting
\end{abstract}

Yalova Üniversitesi Temel İslam Bilimleri Yüksek Lisans Öğrencisi, fatihcankurt@gmail.com. YIL: 5 SAYI: 10 
- YALOVA SOSYAL BILIMLER DERGISI

a key element of reading so that the recitation of the Quran is decremented the differences in society according to these characteristics give the properties and read the language have been emerged with. In this study, the reading of the Quran in different formats and forms of this brilliant reading Tafsir effects to the point has been tried to set an example in terms of Joseph to the duration.

Keywords: Quran, Tafsir, Qiraat

\section{Giriş}

Tefsir, sözlük manası olarak “açıklamak, yorumlamak” manasına gelmekle birlikte, terim manası olarak Kur'ân-1 Kerîm'deki ayetlerin hadisler, sosyal ortam, dil vb. özellikler dikkate alınarak açıklanmaya çalışıldı ilim dalının adıdır.

Kırâat, lügatte “okuma” manasına gelir. "Kur'an Kırâati” şeklindeki terimsel ifade içinde yer aldığı şekliyle ise; Kur'an lafızlarının farklı okunuşları, yani "med (harfleri uzatma), kasr (harfleri uzatmama), hareke, sükun, nokta, i'rab, idgâm, harflerin kalın veya ince okunması, harflerin yerlerinin değişmesi” gibi olguları kapsayan bir ilim dalına ad olmaktadır. "Kırâat farklılıkları” tabiri ise belli başlı kırâat imamlarının Kur'ân-1 Kerîm'deki kelimelerin harf, hareke, med, kasr gibi noktalardaki ihtilafını ifade eder.

$\mathrm{Bu}$ kırâat farklılıkları, kendilerine nispet edilen kırâat imamlarının isimleri altında nesilden nesile aktarıla gelmiş ve günümüzde halen bu ilmi tahsil etmiş olan "kurrâ hafızlar" tarafından bu emanet gelecek nesillere aktarılmaktadır. Genel kabule göre yedisi mütevatir üçü meşhur olmak üzere sahih olarak kabul edilen "on kıraat" tasnifi içerisinde yer alan kırâat imamları şunlardır: 1-Nâfi b b. Abdurrahman (ö.169/785), 2-İbn Kesir (ö.120/738), 3-Ebû Amr b. Alâ (ö.154/771), 4-İbn Âmir (ö.118/736), 5-Âsım b. Behdele (ö.127/745), 6-Hamza b. Habîb (ö.156/773), 7-Kisâî (ö.189/805), 8-Ebû Ca'fer el-Kârî (ö.132/749), 9-Ya'kûb el-Hadramî (ö.205/821), 10-Halef b. Hişâm (ö.229/844).

YIL: 5 SAYI: 10 
Bu makale hazırlanırken farklı kırâat imamlarının Yûsuf Sûresi üzerindeki okuyuş farklılıkları ve bu okuyuş farklılıklarının tefsir-mana bakımından etkileri tespit edilerek, "kırâatlerin tefsire etkisi" konusunda Kırâat ve Tefsir alanına sûre bazında da olsa yarar sağlama amacı gözetilmiştir.

Yûsuf Sûresi, Kur'ân-1 Kerîm'deki sıralama bakımından 12. sûredir. Sûrede Hz. Yûsuf'un hayatından kesitler içeren ve Kurân-1 Kerîm tarafindan "en güzel kıssa" olarak nitelendirilen kıssa konu edildiği için bu adı almıştır. İlk üç ayeti Medine dönemi, diğer ayetleri Mekke döneminde nâzil olan sûre 111 ayetten meydana gelmektedir. Sûrede Hz. Yûsuf'un ibretlerle dolu kıssası ayrıntılı olarak anlatılmaktadır ve sûrenin son bölümünde birtakım uyarılara ve nasihatlere yer verilmektedir. Sûre, Kur'an'da zikredilen peygamberler ile ilgili kıssaların farklı yerlerde parçalar halinde anlatılmasının aksine, Yûsuf peygamberin kıssasının bütün olarak anlatıldığı tek sûre olma özelliğine de sahiptir.

Sûrede üzerine durulan başlıca hususlar şunlardır: Rüya yorumu, kardeşler arası ilişkiler, şahitlikte ve hakemlikte adaletten ayrılmama, günah işlemekten Allah'a sığınma, Allah'ın emirlerine uyma, haksızlık karşısında yılmadan hak arama ve Allah'a sığınma, ibadeti Allah'a has kılma, tedbirli olma, ana-baba ve akrabayı görüp gözetme, takva sahibi olma, zulümden kaçınma, sabırlı olma, affetme, şımarmama, geçmiş toplumların başlarına gelenlerden ibret alma, Kur'an'ın kendinden önceki kitapları tasdik eden rahmet ve hidayet rehberi olan bir kitap olduğunu bilme. 
$234 \cdot$ YALOVA SOSYAL BILIMLER DERGISI

\section{Yûsuf Sûresi'nde Okuyuş Farklılığı Olan Ayetler ve Tefsire Etkileri}

\section{Yûsuf Sûresi 23. Ayet}

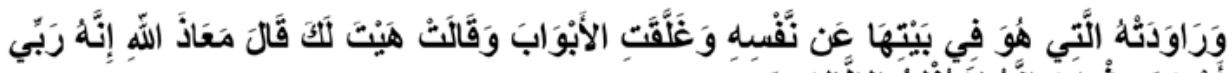

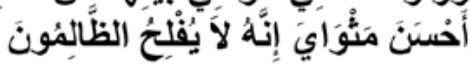

"Evinde bulunduğu kadın, onun nefsinden murat almak istedi, kapılarl iyice kapattı ve «Haydi gel!» dedi. O da «(Hâşâ) Allah'a sı̆̆ınırım! Zira kocan benim velinimetimdir, bana güzel davrandl. Gerçek şu ki, zalimler iflah olmaz!» dedi."

Kıssaya göre, farklı anneden olan kardeşleri hem kendisinde bulunan bazı özellikler hem de babalarının ona daha düşkün olması sebebiyle Hz. Yûsuf'a kin ile kıskançlık beslemektedirler. Bu kıskançlık onları Hz. Yûsuf'u bir şekilde ortadan kaldırmaya iter. Bunun neticesi olarak da onu öldürmek yerine bir kuyuya atmaya karar verirler ve babalarından zor bir şekilde aldıkları izin neticesinde onu evden uzaklaştırırlar ve kuyuya atarlar. Hz. Yûsuf daha sonra oradan geçen kervan tarafindan alınır ve köle olarak birkaç farklı kişiye satılır. Son olarak Mısır devlet erkânından Kur'an'da “aziz” olarak nitelenen kişi tarafından satın alınır. Yüz güzelliğiyle bilinen Hz. Yûsuf evin hanımı olan "azizin karısı” tarafından çok beğenilmektedir. Bunun neticesi olarak da yukarıdaki ayette anlatıldığı gibi ondan faydalanmak ister ve defalarca Hz. Yûsuf tarafından reddedilir. Nihayetinde azizin karısının bu isteğini yerine getirmediği için zindana atılır ve senelerce zindan hayatı yaşar. $\mathrm{Bu}$ ayet azizin karısının $\mathrm{Hz}$. Yûsuf'a kendisini teklif ettiği sahnelerden birisinden bahsetmektedir.

\subsection{Kırâat Farklılıkları}

$\mathrm{Bu}$ ayette geçen "هَيْتَّ" kelimesinde kırâat ihtilâfı bulunmaktadır.

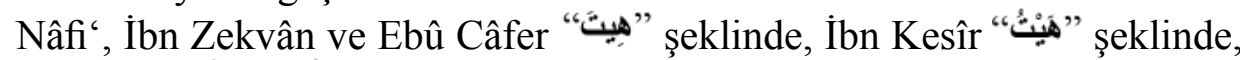

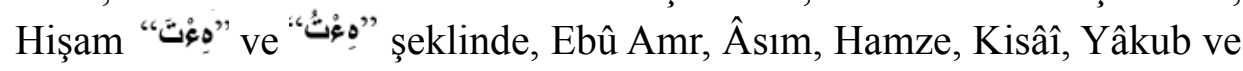




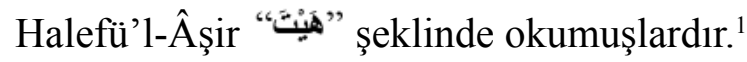

\subsection{Tefsire Etkisi}

Buradaki kırâat farklılıklarının aynı manaya geldiğini söyleyenler ol-

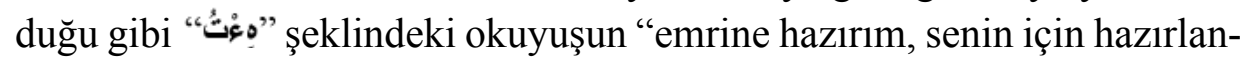
dım" şeklinde bir manaya geldiği de ifade edilmiştir. ${ }^{2}$ Bu şekildeki kırâat farklılığı ile mana daha da kapsamlı hale gelmiş olmakta ve "haydi gel, senin için hazırlandım, emrine hazırım” şeklinde bütün bir manaya sahip olmaktadır.

\section{Yûsuf Sûresi 24. Ayet}

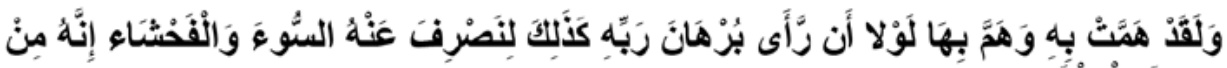

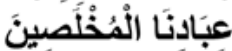

"Ant olsun ki, kadın ona meyletti. Ĕger Rabbinin işaret ve ikazını görmeseydi o da kadına meyletmişti. Isşte böylece biz, kötülük ve fuhşu ondan uzaklaştırmak için (delilimizi gösterdik). Şüphesiz o ihlaslı kullarımızdan$d l . "$

$\mathrm{Bu}$ ayette zikredilen olayla peygamberlerin de, Allah'ın onları günahlardan muhafazası olmadığı takdirde diğer insanlardan farkı olmadığına; beşerî, nefsanî özellikler taşıdığına dikkat çekilmektedir. Dolayısı ile "azizin karısı" Hz. Yûsuf'a açık bir şekilde zina teklifi yapınca -eğer Rabbi tarafından bir ikaz gelmemiş olsa- Hz. Yûsuf'un da ona meyledeceği, onun dileğini yerine getireceği bildirilmektedir.

\subsection{Kırâat Farklılıkları}

Ayette geçen "الْفَفْلَصِينَ" kelimesinde kırâat ihtilâfı bulunmaktadır. Nâfi', Âsım, Hamze, Kisâî, Ebû Câ'fer ve Halefü'l-Âşir ve İbn Zekvân 1 İbnü'l-Cezerî, en-Neşr fi'l-Kirâati'l-Aşr, II, 293.

2 Taberî, Câmiu'l-Beyân an Te'vîli Âyi'l-Kur'ân, XII, 178; Zemahşer̂i, el-Keşşâf an Hakâiki 't-Tenzîl, II, 310; Râzî, Mefâtîhu'l-Ğayb, XVIII, 113. 


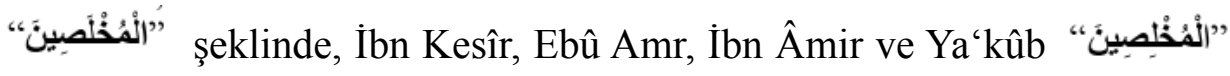
şeklinde okumuşlardır. ${ }^{3}$

\subsection{Tefsire Etkisi}

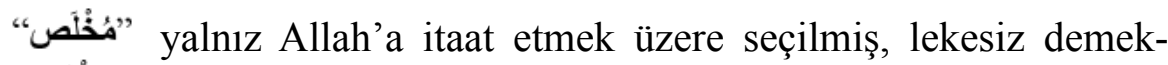

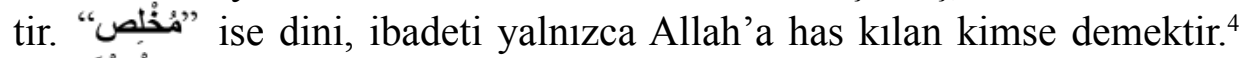

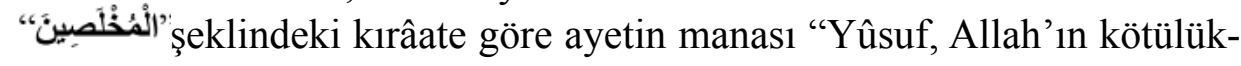
lerden arındırdığı, hâlis ve ihlaslı kıldığı kimselerdendi" şeklinde anlaşı1makla birlikte, Sâd Sûresi 46. ayette ifade edilen Hz. İbrahim'in zürriyetinden olmasının da kastedildiğini ifade edenler olmuştur. ${ }^{5}$

"الُْخْلصِينَ" şeklindeki kırâat ise "Yûsuf dinini yalnız Allah'a has kılan ihlaslı kullarımızdandı" şeklinde bir mana ifade etmektedir.

\section{Yûsuf Sûresi 62. Ayet}

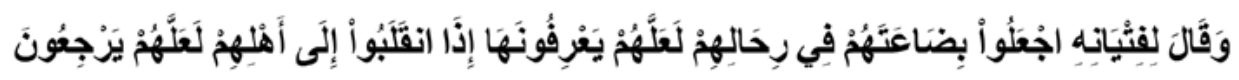

"Yûsuf, adamlarına dedi ki: Onları ödedikleri zahire bedellerini, yüklerinin içine koyun. Umulur ki ailelerine varınca onu anlarlar da belki yine dönüp gelirler."

Ayet, Mısır'da yaşanan kitlık zamanında Hz. Yûsuf'tan getirdikleri eşya karşılığında erzak almaya gelen ve kendisini tanımayan kardeşlerinin farkına varıp da geri dönmelerini umarak aldıkları erzaklar karşıllğında vermiş oldukları malları, onlar farkına varmadan erzaklarının içine konulması için verdiği talimat ile ilgilidir.

3 İbnü'l-Cezerî, en-Neşr fi'l-Kırâati'l-Aşr, II, 295.

4 Elmal11, Hak Dini Kur'ân Dili, IV, 2856.

5 Taberî, Câmiu'l-Beyân an Te 'vîli Âyi'l-Kur'ân, XII, 178; Râzî, Mefâtîhu'l-Ğayb, XVIII, 113.

YIL: 5 SAYI: 10 


\subsection{Kırâat Farklılıkları}

Ayette geçen “'فِقيَّانْهِ" kelimesini:

Nâfi', İbn Kesîr, Ebû Amr, İbn Âmir, Ebû Bekr Şu'be, Ebû Ca'fer ve

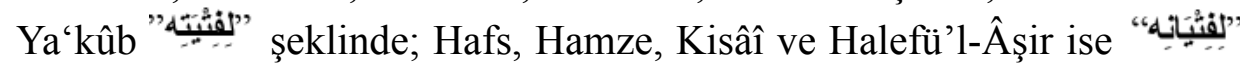
şeklinde okumuşlardır. ${ }^{6}$

\subsection{Tefsire Etkisi}

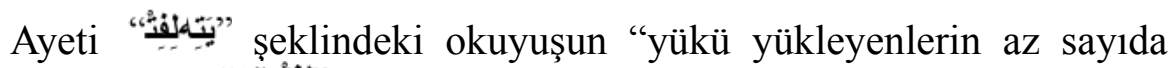

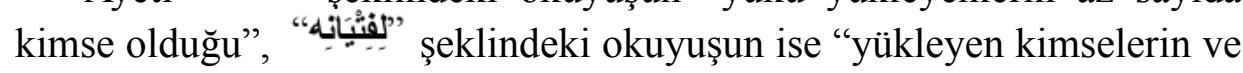
yüklenen şeylerin çok olduğu" manasında olduğunu söyleyenler olmakla birlikte, her iki okuyuşun aynı manaya sahip olduğunu söyleyenler de olmuştur. $^{7}$

\section{Yûsuf Sûresi 90. Ayet}

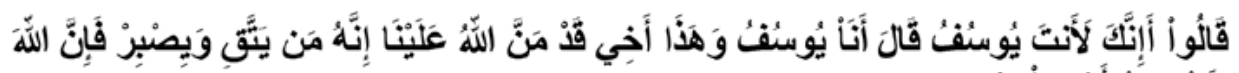

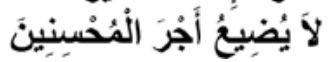

“Kardeşleri, 'Yoksa sen, sen Yûsuf musun?' dediler. O da, 'Ben Yûsuf'um, bu da kardeşim. Allah, bize iyilikte bulundu. Çünkü kim kötülükten sakınır ve sabrederse, şüphesiz Allah iyilik yapanların mükâfatın zayi etmez'dedi."

Ayette, Hz. Yûsuf'la erzak alımından sonra tekrar karşılaşan kardeşlerinin, onun seneler önce kuyuya attıkları kardeşleri olduğunu anlamaları, bunun karşısında şaşkınlıklarını dile getirmeleri ve Hz. Yûsuf'un bu vesile ile onlara "kötülükten sakınıp sabredenlerin mükâfatını Allah'ın zayi etmeyeceğini" hatırlatmasından bahsedilir.

6 İbnü'l-Cezerî, en-Neşr fi'l-Kırâati'l-Aşr, II, 295.

7 Ebû Zür'a, Huccetü'l-Kırâat, 361; Râzî, Mefâtîhu'l-Ğayb, XVIII, 168. 
238 - YALOVA SOSYAL BILIMLER DERGISI

\subsection{Kırâat Farklılıkları}

Burada kırâat farklılı̆ğ olan kelimeyi:

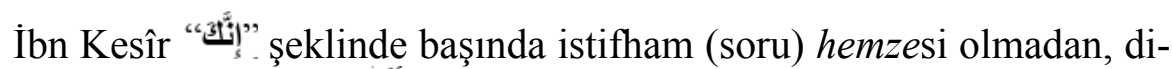

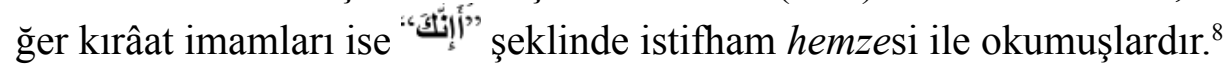

\subsection{Tefsire Etkisi}

“أإنَّة "şeklindeki okuyuşa göre “gerçekten sen Yûsuf musun?” manası çıkarken “" “" şeklindeki okuyuşa göre ise "gerçekten sen Yûsuf'sun” manası çıkmaktadır. ${ }^{9}$

\section{Yûsuf Sûresi 110. Ayet}

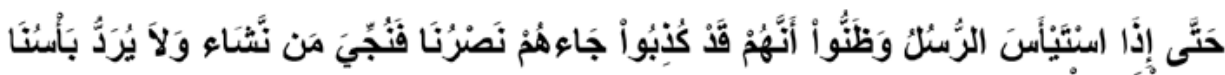

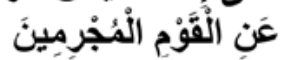

"Nihayet peygamberler ümitlerini kesecek hâle gelip yalanlandıklarını düşündükleri sırada, onlara yardımımız geldi de, böylece dilediğimiz kimseler kurtuluşa erdirildi. Azabımı ise, suçlular topluluğundan geri çevrilemez."

Ayette daha önceki peygamberlerden örnek verilerek, onların kendilerine inanacak kimse olmayacağından ümit kestikleri ve yalancı çıkarıldıklarını hissedip üzüntüye kapıldıkları sırada, onlara Allah'ın yardımının yetişip bu sıkıntıdan kurtarıldıklarından; ancak inkârcıların, suçluların azaptan kurtulamadıklarından ve kurtulamayacaklarından bahsedilmektedir.

\subsection{Kırâat Farklılıkları}

Söz konusu ayetteki kırâat farklılığı olan kelimeyi:

Âsım, Hamze, Kisâî, Ebû Ca“fer ve Halefü'l-Âşir " "sُْْبُو" şeklinde

8 İbnü'l-Cezerî, en-Neşr fi'l-Kırâati'l-Aşr, II, 296.

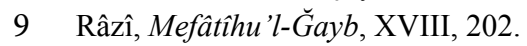

YIL: 5 SAYI: 10 


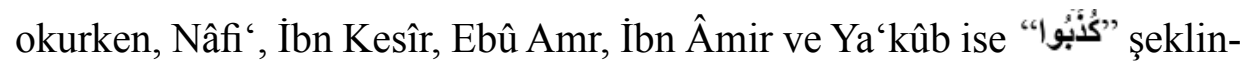
de okumuşlardır. ${ }^{10}$

\subsection{Tefsir'e Etkisi}

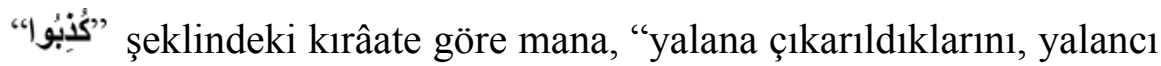
durumuna düşürüldüklerini, yalancılıkla suçlandıklarını sandılar" şeklindedir. Buradaki "zan"nın peygamberlere değil onların kavimlerine ait olduğu, kavimlerin peygamberlerine vadedilen yardım ve zafer konusunda yalancı durumuna düştükleri belirtilmiştir.

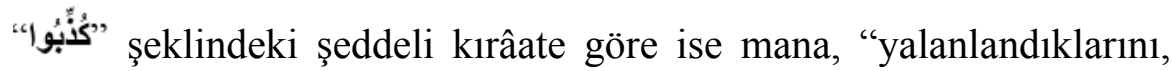
inkâr edildiklerini zannettiler" şeklinde olur. Buradaki "zan", "kesin bilgi" anlamında kullanılmış olduğu görüşüne göre "Peygamberler gönderildikleri halkın iman etmeyeceklerine, kendilerini yalanladıklarına iyice inandılar" anlamı ortaya çıkarken; "zannetme" manasında olduğu görüşüne göre de "Peygamberler kendilerine inanan kimselerin, Allah'ın yardımının gelmesi hususunda kendilerini yalanlayacaklarını zannettikleri, endişe ettikleri sırada Allah'ın yardımı geldi" anlamı ortaya çıkmaktadır. ${ }^{11}$

\section{Sonuç}

Kırâat faklılıklarının Yûsuf Sûresi'ne etkisinin araştırılmış olduğu bu makalede, Kur'ân-1 Kerîm'in sıralama olarak 12. sûresi olan Yûsuf Sûresinde meşhur kurrâlar (kırâat imamları)'ın birbirinden farklı şekilde okumuş oldukları yerlerin olup olmadığı ilgili kaynaklardan tahlil edilmiş ve $23,24,62,90$ ve 110 . ayetlerdeki 5 farklı kelimenin kurrâ tarafindan ihtilaf ile okunduğu tespit edilmiştir.

Söz konusu ayetlerdeki kırâat ihtilaflarının manaya etki eden yönünün olup olmadığı -kaynakçada da belirtilen- muteber tefsir kitapları taranarak incelenmiş ve sonuç olarak ayetlerde ortaya çıkan farklı okuyuş biçimleri-

10 İbnü'l-Cezerî, en-Neşr fi'l-Kırâati'l-Aşr, II, 296.

11 Taberî, Câmiu'l-Beyân an Te'vîli Âyi'l-Kur'ân, XIII, 85; Ebû Zür'a, Huccetü'l-Kırâat, 366; Zemahşerî, el-Keşşấf an Hakâiki 't-Tenzîl, II, 347; Râzî, Mefâtîhu'l-Ğayb, XVIII, 226. 
$240 \cdot$ YALOVA SOSYAL BILIMLER DERGISI

nin birbirine yakın manaları veya benzer manaları ihtiva ettiği görülmüştür.

Her ne kadar bu okuyuş farklılıklarının manayı tamamen değiştirmediği görülse de, bu farklı kırâatlerin manayı genişletmesi, derinleştirmesi açısından, dolayısıyla Kur'ân-1 Kerîm'in ne kadar veciz bir kitap olduğunu bir kez daha ortaya koyması bakımından, bu çalışmanın yapılmış olmasının alana faydalı olacağı kanaati tarafımızca benimsenmiştir.

\section{KAYNAKÇA}

Çetin, Abdurrahman, Kırâatların Tefsire Etkisi, Ensar Neşriyat, İstanbul 2012.

Demirci, Muhsin, Tefsir Usulü, İFAV, İstanbul 2008.

Ebû Zür'a, Abdurrahman b. Muhammed (ö.403), Huccetü' 'l-Kırâat, Beyrut 1972, 2. bs.

Elmal111, Yazır Hamdi (ö.1944), Hak Dini Kur'ân Dili, İstanbul ts.; Sadeleștirmesi: İsmail Karaçam; Emin Işık; Nurettin Bolelli; Abdullah Yücel, İstanbul 1993.

İbnü'l-Cezeri, Ebü'l-Hayr Şemseddin Muhammed b. Muhammed (ö.833/1429), en-Neşr fi'l-Kırâati'l-Aşrr, thk. Ali Muhammed Dabba, Misır ts.

Râzî, Fahruddîn Muhammed b. Ömer (ö.606/1209), Mefâtîhu'l-Gayb, Misır 1938; çev. Suat Yıldırım, Lütfullah Cebeci, Sadık Kılıç, C. Sadık Doğru, Ankara 1988.

Taberî, Muhammed b. Cerîr (ö.310/922), Câmiu' 'l-Beyân an Te 'vîli Ayyi 'l-Kur 'ân, 3. bs., Misir 1968.

Zemahşerî, Cârullah Mahmud b. Ömer (ö.538/1143), el-Keş̧̧âf an Hakâiki'tTenzîl, Beyrut ts.

YIL: 5 SAYI: 10 